\title{
In Search of the "Fundamental Rule" of Supportive Psychotherapy
}

Jeffrey R. Sarnoff, MD

Thomas Jefferson University Hospital

Follow this and additional works at: https://jdc.jefferson.edu/jeffjpsychiatry

Part of the Psychiatry Commons

Let us know how access to this document benefits you

\section{Recommended Citation}

Sarnoff, MD, Jeffrey R. (1986) "In Search of the "Fundamental Rule" of Supportive Psychotherapy," Jefferson Journal of Psychiatry. Vol. 4 : Iss. 1 , Article 14.

DOI: https://doi.org/10.29046/JJP.004.1.010

Available at: https://jdc.jefferson.edu/jeffjpsychiatry/vol4/iss1/14

This Article is brought to you for free and open access by the Jefferson Digital Commons. The Jefferson Digital Commons is a service of Thomas Jefferson University's Center for Teaching and Learning (CTL). The Commons is a showcase for Jefferson books and journals, peer-reviewed scholarly publications, unique historical collections from the University archives, and teaching tools. The Jefferson Digital Commons allows researchers and interested readers anywhere in the world to learn about and keep up to date with Jefferson scholarship. This article has been accepted for inclusion in Jefferson Journal of Psychiatry by an authorized administrator of the Jefferson Digital Commons. For more information, please contact: JeffersonDigitalCommons@jefferson.edu. 


\title{
In Search of the "Fundamental Rule" of Supportive Psychotherapy
}

\author{
THE PRACTICE OF SUPPORTIVE PSYCHOTHERAPY \\ David S. Werman, M.D. \\ New York: Brunner/Mazel \\ 1984. 186 pages, $\$ 25.00$
}

Jeffrey R. Sarnoff, M.D.

Early in my first year of residency training in psychiatry, while working between acute-care inpatient units and a busy crisis service, it appeared that virtually every patient was said to have been treated with supportive psychotherapy, in conjunction with psychotropic medication. This appearance was deceiving, and if not for thorough supervision, reading, discussion with faculty and peers, and autocritical review, I might still believe that my earliest, and perhaps sickest, patients were indeed treated with supportive psychotherapy. In retrospect, some were and some were not; the explanation for this discrepancy came with the realization that I did not have very clear ideas about the nature of supportive psychotherapy, its indications and contraindications, its technical practice, its efficacy, or its derivation from psychoanalytic theory. Without this knowledge, I could not practice supportive psychotherapy.

As I later appreciated, an inexperienced therapist can no better implement supportive psychotherapy than any other modality, whether it be expressive (insight-oriented) psychotherapy or psychoanalysis, unless carefully taught, didactically and clinically. Unfortunately, supportive psychotherapy, thought of by many as a poor cousin in the family of psychotherapeutic modalities, has gone without its own course of study in many psychiatric residencies, even though so many patients might benefit from it if practiced proficiently.

During my second year of training, in transition from inpatient to outpatient work, a supervisor recommended to me a paper by David S. Werman entitled "Technical Aspects of Supportive Psychotherapy" (1). The paper was useful in that it elucidated specific contradistinctions between supportive and

The author wishes to thank S. Akhtar, M.D., Professor of Psychiatry, Thomas Jefferson University, for his supervision in psychotherapy, and H. Schwartz, M.D., Director of Residency Training, Thomas Jefferson University, for reviewing a draft of this paper. Dr. Sarnoff is a third-year resident at Thomas Jefferson University, Philadelphia, Pennsylvania. 
insight-oriented psychotherapy. Werman wrote:

... technical differences between insight-oriented psychotherapy and supportive psychotherapy are unclear, particularly in the practice of supportive psychotherapy where one regularly sees a stereotyped adherence to procedures appropriate to psychoanalysis or insightoriented psychotherapy. This is especially unfortunate because psychoanalytic theory remains the most useful conceptualization of both these psychotherapies. (2)

In delineating the technical aspects of supportive psychotherapy, Werman makes clear that this modality can, to use Winnicott's phrase, provide a "holding environment" (3) in which a patient can be protected from internal and external destructive factors. The therapist may need to be active, direct, explicit, and provide the patient with a view of his knowledge regarding his condition. Technical neutrality is not maintained to the point that a transference neurosis would develop, and interpretation is not a cornerstone of the therapy. Defenses are addressed when they are grossly maladaptive; healthier defenses are bolstered.

Werman recognizes that not only is supportive psychotherapy in itself often undervalued, but so are many of the patients treated with it. Supportive psychotherapy has been, to many residents and supervisors, a treatment of exclusion, applied to patients thought to be incapable of treatment modalities requiring insight. Given my difficulties with the conceptualization and practice of supportive psychotherapy, it was useful when a clinical supervisor of mine, a psychoanalyst, illustrated to me that supportive psychotherapy, while derived from psychoanalytic theory, lies on a continuum with it. This illustration was made by clinical example-how could the psychotherapist respond to a given comment, whether uttered by a patient in the context of psychoanalysis, expressive, or supportive psychotherapy. Indeed, for the patient stating "I'm sorry I'm late, my train was delayed," a proper response must be based, in all cases, upon a correct psychodynamic understanding of the patient; the differences in responses would center around the degree and nature of the interpretation, if any - that is, to what degree would the therapist focus on the intrapsychic world of the patient, between himself and the patient, and between the patient and external reality. The notion of a continuum ranging from psychoanalysis to supportive psychotherapy gave me the glue with which to begin solidifying many of the previously seeming disparate ideas about the different modalities.

Dr. Werman, in seeking to clarify the theory and technique of supportive psychotherapy beyond his paper, has recently published a book, The Practice of Supportive Psychotherapy. Certainly, there is a place for such a work. Divided into 17 chapters, with references and an index, the book is clearly and simply written. Chapters 1-9 provide a wide introduction, chapters 10-13 explore "Typical Situations and Techniques"; chapters 14-17 examine the place of the dream in 
supportive psychotherapy, interruption, termination, and the changeover to insight-oriented psychotherapy. The book furthers the cause for supportive psychotherapy as a valid psychotherapeutic method, and in doing so dispels the myth that what some would call reassurance, and others would call chit-chat, are synonymous with supportive psychotherapy.

While many clinical vignettes appear throughout the text, they are relevant, yet not sufficiently explored or developed. Most chapters are divided into several sub-sections, which are occasionally useful but more often frustrating, for just as an idea is put forth, it is concluded, giving the book a lack of continuity. Neither extensively technical nor theoretical, the work seeks a compromise between the two, but succeeds inconsistently. In one instance, Werman writes:

Patients who have poor object relations should be considered for supportive psychotherapy because that form of treatment does not depend on the development of transference.

With this, an 18-line subsection on "Relationships to Others" (p. 24) ends, and the reader must refer to chapter 8 , page 80 , "Transference and Countertransference," to explore the matter further. Surely, while supportive psychotherapy does not depend on the development of a transference neurosis, transference as a phenomenon in psychotherapy is hard to avoid, and essential to understand, if interpreted to varying degrees. The book's credibility would be enhanced if theory and practice were more effectively interwoven, in this case by means of a statement specifically linking a therapist's understanding of a patient's object relations, to his propensity for various levels of intervention. It is in this regard that the clinical vignettes could be more effectively developed.

While the above illustrates a possibly controversial theoretical point, the book also contains technical ideas which are open to question, or at least deserve more extensive consideration by the author. For instance, Werman writes:

Before beginning treatment, I recommend to patients in supportive psychotherapy that they tell whatever thoughts or feelings are going through their minds during the hour. (p. 37)

That the theory underlying supportive psychotherapy derives from psychoanalytic theory seems acceptable; that the methods should become confluent does not. It is possible that Werman could augment his case in such matters, and regrettable that he does not, because the book is written by an author who clearly cares a great deal about his patients and his clinical method. The lack of a "fundamental rule" for supportive psychotherapy has probably contributed to the common misunderstanding of this modality's practice.

By contrast, the chapter entitled "Supportive Psychotherapy" in Severe Personality Disorders by Otto F. Kernberg (4) elucidates the relevant historical, theoretical, and technical points with great economy of words and compelling, rational exposition. 
Kernberg identifies several misconceptions surrounding supportive psychotherapy, the first of which is that supportive psychotherapy is easy to conduct. He writes that supportive psychotherapy should be taught after a base in the expressive therapies has been solidified; he accounts for supportive psychotherapy's greater difficulty because of its inherent contraindication toward explicit examination and eventual interpretation of the transference, leaving the therapist to rely a great deal on inference and the observation of transference manifestations. The second misconception identified by Kernberg is that

primitive ego defenses must be left undisturbed because given the supposedly frail equilibrium of impulse-defenses, interpreting them may produce further regression . . . one of the main technical requirements of supportive psychotherapy is noninterpretive but consistent work with primitive defenses in the therapeutic interaction. (pp. 153-154)

Additionally described is the misconception that not addressing manifestations of negative transference when they appear, may eventually lead a patient to identify with the therapist's "consistently friendly, patient, permissive attitude" (p. 154). The final misconception noted by Kernberg is "the most widespread of all, that the sicker the patient, the less he can be expected to participate actively in psychotherapy." Kernberg notes that if supportive psychotherapy is "done ... to the patient ... this fosters passivity and makes a contribution to treatment stalemates." (p. 155)

Going on to describe basic techniques of supportive psychotherapy, Kernberg provides the reader with the clear notion that the patient's primitive defenses must be explored within the context of his present condition; that the patient must come to recognize his stereotyped, maladaptive responses and how these may be influenced by such primitive defenses as denial, splitting, and projective identification. The therapist would, according to Kernberg, work exclusively with conscious and preconscious material (p. 157), and avoid the giving of advice, which would "exploit unanalyzed primitive transference dispositions" (p. 157); he would structure the treatment sessions, and continually strive to relate ongoing clinical material to the previously clarified and agreedupon goals of treatment. Transference is managed principally by the exploration of its manifest negative manifestations; moderately intense positive transference manifestations may be used in the therapy but the therapist is cautioned that intense, primitive idealization must be actively, promptly dealt with or it may lead to eventual devaluation that could disrupt the therapeutic process.

For someone wishing to read about supportive psychotherapy, I would recommend Werman's paper, "Technical Aspects of Supportive Psychotherapy," followed by Kernberg's above-mentioned chapter in Severe Personality Disorders. I hope that Dr. Werman will expand his book to a more comprehensive volume. 


\section{REFERENCES}

1. Werman D: Technical aspects of supportive psychotherapy. The Psychiatric Journal of the University of Ottawa. 6:153-160, 1981

2. Ibid. p. 153

3. Winnicott D: Psychiatric disorders in terms of infantile maturational processes. The Maturational Process and The Facilitating Environment. New York, International Universities Press: 1965

4. Kernberg O: Severe Personality Disorders: Psychotherapeutic Strategies. New Haven, Yale Universities Press: 1984 